\title{
Effect of Education on Promoting Healthy Lifestyle Behaviors That Prevent Breast Cancer in Middle-Aged Women: Application of Protection Motivation
} Theory

\author{
Zakieh Sadat Hoseini', Hamid Tavakoli Ghouchani ${ }^{2, *}$, Hamidreza Mohaddes Hakak ${ }^{2}$, Hossein Lashkardoost ${ }^{3}$, Ali Mehri ${ }^{4}$, \\ Mehdi Khankolabi ${ }^{2}$, Elahe Salari ${ }^{5}$ \\ 'Department of Public Health, Neyshabur University of Medical Sciences, Neyshabur, Iran \\ ${ }^{2}$ Department of Health Education and Promotion, School of Public Health, North Khorasan University of Medical Sciences, Bojnurd, Iran \\ ${ }^{3}$ Department of Biostatistics and Epidemiology, School of Public Health, North Khorasan University of Medical Sciences, Bojnurd, Iran \\ ${ }^{4}$ Department of Health Education, School of Public Health, Sabzevar University of Medical Sciences, Sabzevar, Iran \\ ${ }^{5}$ Department of Nursing, School of Nursing and Midwifery, North Khorasan University of Medical Sciences, Bojnurd, Iran
}

Background: In recent years, an increased incidence of breast cancer has made this disease the most common malignancy among Iranian women. Since education plays an important role in the implementation of preventive behaviors in breast cancer treatment, this study investigates the effect of educational interventions on the promotion of lifestyle-related behaviors that prevent breast cancer in middle-aged women.

Methods: In this randomized control study, 120 women referred to Neyshabur Health Services Centers were randomly selected and divided into two groups: an intervention group (60 subjects) and a control group (60 subjects). An educational intervention was carried out over five sessions, based on protective motivation theory constructs. Participants completed a researcher-designed questionnaire immediately and again 2 months after the intervention. The data were analyzed using IBM SPSS ver. 19.0 software (IBM Corp., Armonk, NY, USA).

Results: The results revealed a significant difference between the mean scores of participants exposed to protective motivation theory, awareness, and physical activities immediately and also 2 months after the intervention $(\mathrm{P}<0.05)$. Although the healthy diet scores of the two groups differed significantly immediately after the educational intervention $(\mathrm{P}<0.05)$, there was no significant difference between the groups 2 months after the intervention $(\mathrm{P}<0.05)$.

Conclusion: Given the effective role of education in protective motivation theory and the physical activity levels of the women who participated in this research, it seems clear that the women's financial status shaped their ability to consume more fruits and vegetables. As this social element impacts the health of individuals, training programs alone cannot succeed.

Keywords: Motivation; Life Style; Breast Neoplasms; Prevention and Control; Health Behavior; Health Education

Received: December 13, 2019, Revised: January 22, 2020, Accepted: January 30, 2020

*Corresponding Author: Hamid Tavakoli Ghouchani https://orcid.org/0000-0003-3289-7767

Tel: +98-09155841956, Fax: +98-583-224-0524, E-mail: h.tavakoli@nkums.ac.ir 


\section{INTRODUCTION}

Today, cancer is considered one of the most significant health problems worldwide. ${ }^{1)}$ Among various types of cancer, breast cancer accounts for a large percentage of deaths, including $30 \%$ of newly diagnosed cancer cases. ${ }^{2)}$ About 1.5 million women are diagnosed every year with breast cancer; in 2017, approximately 252,710 breast cancer cases were diagnosed worldwide. Of these, approximately 40,610 patients died of the disease. ${ }^{3)}$ The highest disease frequency was observed in women aged $45-65$ and $80-85 .{ }^{4)}$ Over the past 30 years, the incidence of breast cancer has doubled in Iran. Given the increase in life expectancy and population aging, breast cancer cases in Iran are projected to increase to 63 cases per 100,000 women by $2020 .^{5,6)}$

Evidence has shown that $30 \%-40 \%$ of cancers can be controlled through a healthy lifestyle. These include breast cancer, which is considered to be a lifestyle-related cancer. ${ }^{7)}$ Developing an awareness of the signs and symptoms of breast cancer and adopting healthy lifestyle behaviors is a recommended strategy for controlling breast cancer in low- and middle-income countries. It is therefore essential to adjust educational programs to raise awareness of breast cancer. ${ }^{8)}$ According to the literature, high-fat diets increase the risk of breast cancer, while eating fruits and vegetables and engaging in high levels of physical activity can reduce the risk. ${ }^{9,10)}$ However, a significant number of women consume less than the recommended amount of fruit and vegetables per day. The American Cancer Society recommends that women should get 150-300 minutes of moderate intensity or 75-150 minutes of vigorous intensity activity each week (or a combination of these). Getting to or exceeding the upper limit of 300 minutes is ideal and Follows a healthy eating pattern includes the consumption of at least 2 cups of vegetables and 1.5 cups of fruit each day. To help achieve that recommendation, consumers are encouraged to fill half their plate with vegetables and fruits at meals and snacks. ${ }^{11)}$

Protection motivation theory is one of the main sociological theories and models in this field. Rogers ${ }^{12)}$ believes that fear can increase positive protection incentives through six constructs, including self-efficacy, response effectiveness, response cost, perceived vulnerability, perceived severity, and perceived rewards. The elements of this theory are very important in predicting behaviors that prevent cancer. ${ }^{13)}$ Despite the increasing trend in breast cancer cases, there are low levels of adoption of healthy eating, physical activity, and other preventative lifestyle-related behaviors among women. So far, no study has focused on the extent to which healthy-lifestyle education can help to prevent breast cancer in this age group, based on protection motivation theory. To address this gap, the present study has examined the impact of education on middle-aged women in Neyshabur by promoting healthylifestyle behaviors known to prevent breast cancer.

\section{METHODS}

\section{Participants}

The present study was a randomized controlled trial. The study popu- lation consisted of women between the ages of 30 and 69 , referred to health centers in Neyshabur city. In accordance with a previous similar study, ${ }^{14)}$ and accounting for potential dropouts, the sample size was 60 people in each group. The sampling method was a multistage clustering method. First, the city of Neyshabur was divided into three regions: the north of the city, the city center, and the south of the city. In each region, two centers were selected using the random blocking method. Through a process of simple randomization, one center was designated the control group and the other the intervention group. During the next stage, 120 women eligible to participate in the study were selected. The criteria included reading and writing skills, no history of breast-related disease, and being between 30 and 69 years old. Women who missed more than one educational session were excluded. This research was carried out in 2018, following approval from the Ethics Committee of North Khorasan University of Medical Sciences (ethics code 960167).

\section{Instrument}

Data were collected using a self-reporting, researcher-designed questionnaire divided into four sections. The questionnaire items were based on the constructs of protection motivation theory in two ways. First, the researcher searched information centers and examined student theses, reviewed similar questionnaires, and studied related articles. ${ }^{15,16)}$ A needs analysis was then carried out to ascertain the community's beliefs about breast cancer; 20 women between 30 and 69 completed a series of open-ended questions. The researchers used their responses to become more familiar with the beliefs of the community. At this stage, the questionnaire included open-ended questions about protection motivation theory constructs and ways of preventing breast cancer. For example, one question explored the perceived susceptibility structure by asking: "How do you think you are likely to become infected with breast cancer?" Why? To explore perceived severity, the participants were asked, "What do you think will be the consequences of breast cancer to you and your family?" Separate questions explored women's main reasons for failing to implement preventive behaviors. The most important factors underpinning preventive action were researched; based on these results and the first stage of the study, which included a review of the texts, the first draft of the protection motivation theory was designed.

The content validity of the questionnaire was assessed both quantitatively and quantitatively. In the qualitative study of the content, experts were asked to examine the extent to which the questionnaire content and research purpose were coordinated; their feedback was then applied to the questionnaire. For the quantitative analysis of the questionnaire content, the content validity ratio (CVR) and content validity index (CVI) were evaluated by 10 experts ( 8 health-promotion specialists and 2 midwifery specialists). The CVI and CVR values were considered to be higher than 0.79 and 0.62 , respectively. To determine its face validity, the modified questionnaire was tested in a pilot test. To determine reliability, the validated questionnaire was distributed to 20 individuals in the target groups. After collecting and extracting the 
data, Cronbach's $\alpha$ values were calculated; values of 0.7 were considered acceptable.

The final version of the questionnaire consisted of four sections: demographic questions, seven questions related to awareness, 41 questions related to protective motivation theory constructs, and four questions about behaviors related to a healthy diet and physical activity.

To rate the questionnaire in the awareness section, 1 point was awarded for a correct answer, and 0 for a wrong answer or "I don't know." Items related to protective motivation theory structures were scored using a 5-point Likert scale, with responses ranging from "totally disagree" to "totally agree." Regular physical-activity behaviors were rated using a scale that ranged from 0 (never) to 4 (always). A healthy diet was assessed through three questions, with responses ranging from 0 to 2 . Scores for the awareness items ranged from $0-7$, perceived sensitivity from 6-30, perceived severity from 7-35, fear from 6-30, efficacy of perceived response from 4-20, perceived reward from 4-20, perceived cost from 5-25, self-efficacy from 4-20, motivation from $5-25$, physical activity from $0-4$, and a healthy diet from $0-6$.

\section{Treatment}

The educational intervention was based on a cross-sectional study and the initial needs assessment of the intervention group. It was implemented in five 60-minute sessions, based on protection motivation theory constructs. The first session began with an introduction to the rules and regulations of the training sessions, the purpose of the study, and participant responsibilities. Participants watched a movie about breast cancer statistics and complications to increase their sensitivity and intensify their comprehension. The second session introduced training designed to increase the effectiveness of the women's responses; the effective use of healthy-lifestyle behaviors was discussed as a method of preventing the disease. During the third training session, each woman began by outlining the obstacles she faced in adopting behaviors associated with a healthy lifestyle. The participants were then asked to suggest ways of overcoming barriers during a brainstorming session. They presented effective strategies for overcoming barriers. The women were then asked to share successful experiences of implementing these behaviors. During the fourth session, a movie was used to introduce steps toward adopting healthy-lifestyle behaviors to increase the women's self-efficacy. During the fifth session, a patient with breast cancer was invited to discuss her problems and the effectiveness of lifestyle-related behaviors with the group; this session was designed to increase the women's motivation to adopt these behaviors (Table 1). The post-test was performed immediately, and again 2 months after the educational intervention. In this study, ethical research codes were followed at all stages of research; these guaranteed anonymity of information, informed consent, the voluntary presence of all participants, and the confidentiality of information shared with researchers.

\section{Data analysis}

The collected data were analyzed using descriptive statistics (frequency distribution, mean, and standard deviation [SD]), an independent ttest, chi-square test, Mann-Whitney test, Friedman test, and repeated measures. The level of significance was considered $\mathrm{P}<0.05$.

\section{RESULTS}

The mean age of the women participating in the study was 39.38 years ( $\mathrm{SD}=7.83$ ). Twenty-six (43.3\%) participants in each group had primary or secondary education and 55 (91.7\%) women in each group were housewives; $93.3 \%$ of all participants were married. Moreover, $92.5 \%$

Table 1. Organization of educational sessions in the experimental group

\begin{tabular}{|c|c|c|}
\hline Sessions & Objectives & Summary of topics and activities \\
\hline First & Increased perceived threat of breast cancer & $\begin{array}{l}\text { - Presentation of breast-cancer statistics in women } \\
\text { - Group discussion of the effects of breast cancer on women's lives } \\
\text { - Discussion of women's maladaptive beliefs regarding their lack of vulnerability to breast cancer } \\
\text { - Presentation of an educational film explaining how breast cancer affects different parts of a woman's body }\end{array}$ \\
\hline Second & $\begin{array}{l}\text { Increasing the effectiveness of perceived response } \\
\text { in adopting healthy lifestyle behaviors }\end{array}$ & $\begin{array}{l}\text { - Questions and answers following a presentation on the effective role of a healthy lifestyle in preventing } \\
\text { breast cancer. Statistics showing the impact of a healthy lifestyle on breast cancer prevention } \\
\text { - Distribution of an instructional booklet, entitled "Healthy lifestyle guide" to participants }\end{array}$ \\
\hline Third & $\begin{array}{l}\text { Improving women's attitudes by emphasizing the } \\
\text { costs and rewards of perceived response }\end{array}$ & $\begin{array}{l}\text { - Obstacles that participants began by outlining the obstacles they faced in adopting behaviors associated } \\
\text { with a healthy lifestyle. Development and presentation of effective strategies for overcoming barriers } \\
\text { through brainstorming } \\
\text { - Discussions about the positive and negative emotions of women toward overcoming obstacles to promote } \\
\text { healthy lifestyle behaviors } \\
\text { - Sharing of women's successful experiences of adopting healthy lifestyle behaviors }\end{array}$ \\
\hline Fourth & $\begin{array}{l}\text { Increasing women's self-efficacy in adopting } \\
\text { healthy lifestyle behaviors }\end{array}$ & $\begin{array}{l}\text { - Presentation of an educational film to promote women's skills at practicing various appropriate physical } \\
\text { activities } \\
\text { - Distribution of an educational pamphlet on a healthy diet and its role in preventing breast cancer } \\
\text { - Introduction of time-management strategies to incorporate regular physical activity into women's daily } \\
\text { schedules }\end{array}$ \\
\hline Fifth & $\begin{array}{l}\text { Increasing women's motivation to adopt behaviors } \\
\text { that prevent breast cancer }\end{array}$ & $\begin{array}{l}\text { - A cancer patient's narrative of the problems and limitations of breast cancer and the role of a healthy } \\
\text { lifestyle in preventing the disease } \\
\text { - A group discussion on how to incorporate healthy lifestyle behaviors into women's daily routines }\end{array}$ \\
\hline
\end{tabular}


of the women who participated in this study had no family history of breast disease. The two groups had no significant differences in their demographic variables before the intervention $(\mathrm{P}<0.05)$.

The findings showed that, among the 120 participants prior to the intervention, the highest score among the variables studied related to protection motivation, with subjects obtaining an average of $84.75 \%$ of the achievable score for the construct. The lowest score, among the protection motivation theory constructs, involved the perceived response cost, with women obtaining $39.2 \%$ of the achievable score. The mean scores for physical activity and a healthy diet were $43.51 \%$ and $33.88 \%$, respectively, among all study participants.

The Mann-Whitney test showed that, before the intervention, the two groups had no significant differences in relation to physical-activity variables $(\mathrm{P}<0.05)$, while nearly half $(43.3 \%)$ of the participants reported some physical activity. However, immediately and 2 months after the intervention, the mean regular-physical-activity score differed significantly between the two groups $(\mathrm{P}<0.05)$.

The findings showed no significant difference between the two groups in terms of fruit consumption, vegetable consumption, and type of oil consumption $(\mathrm{P}<0.05)$. At first, more than half of the women surveyed consumed fewer than two units of fruit per day, while $71.7 \%$ of the women in both groups consumed fewer than three units per day. Similarly, nearly half of the women (47.5\%) had a combination of solid and liquid oils in their food baskets. Although there was some increase in the frequency of fruit, vegetable, and vegetable oil consumption in the intervention group immediately and 2 months after the educational intervention, the difference was not significant between the two groups (Table 2).

The results showed a significant difference between the mean scores related to protection motivation theory in the intervention group, both immediately and 2 months after the intervention (Table 3 ).

\section{DISCUSSION}

The findings show that the intervention program had an effect, both immediately and 2 months after the intervention, in relation to protection motivation theory, awareness, and physical activity. However, despite a significant difference in healthy diets immediately after the in-

Table 2. Comparison of healthy lifestyle behaviors in the control and intervention groups during the study

\begin{tabular}{lcccc}
\hline \multicolumn{1}{c}{ Variable } & Before intervention & Immediately after intervention & 2 mo after intervention & P-value (Friedman test) \\
\hline Healthy diet & & & & \\
Control & $3.18 \pm 1.26$ & $3.18 \pm 1.03$ & $3.03 \pm 1.04$ & 0.626 \\
Intervention & $2.91 \pm 1.04$ & $3.61 \pm 1.16$ & $3.35 \pm 1.03$ & 0.073 \\
$\quad$ P-value (Mann-Whitney) & 0.215 & 0.016 & & \\
Physical activity & & & $1.55 \pm 0.94$ & 0.437 \\
Control & $1.58 \pm 0.88$ & $1.61 \pm 1.00$ & $2.21 \pm 1.07$ & 0.001 \\
Intervention & $1.90 \pm 1.02$ & $2.28 \pm 1.20$ & 0.001 & \\
P-value (Mann-Whitney) & 0.087 & 0.001 & & \\
\hline
\end{tabular}

Values are presented as mean \pm standard deviation.

Table 3. Comparison of the mean scores of protective-motivation-theory structures before, immediately after, and 2 months after the intervention in the control and intervention groups

\begin{tabular}{|c|c|c|c|c|c|}
\hline Variable & Category & Before intervention & Immediately after intervention & 2 mo after intervention & P-value (Friedman test) \\
\hline \multirow[t]{2}{*}{ Severity } & Control & $24.66 \pm 5.10$ & $24.56 \pm 4.30$ & $24.08 \pm 4.69$ & 0.515 \\
\hline & Intervention & $24.70 \pm 4.64$ & $27.30 \pm 4.02$ & $26.11 \pm 3.39$ & $<0.001$ \\
\hline \multirow[t]{2}{*}{ Vulnerability } & Control & $19.90 \pm 3.49$ & $19.78 \pm 3.44$ & $19.20 \pm 3.55$ & 0.126 \\
\hline & Intervention & $20.96 \pm 3.72$ & $24.76 \pm 2.87$ & $22.76 \pm 2.54$ & $<0.001$ \\
\hline \multirow[t]{2}{*}{ Protection motivation } & Control & $17.48 \pm 4.43$ & $17.68 \pm 5.35$ & $17.46 \pm 4.18$ & 0.808 \\
\hline & Intervention & $17.65 \pm 3.70$ & $20.15 \pm 3.61$ & $19.50 \pm 3.10$ & $<0.001$ \\
\hline \multirow[t]{2}{*}{ Fear } & Control & $20.36 \pm 5.57$ & $20.55 \pm 4.52$ & $19.93 \pm 4.96$ & 0.423 \\
\hline & Intervention & $20.18 \pm 5.35$ & $23.61 \pm 4.10$ & $22.30 \pm 4.72$ & $<0.001$ \\
\hline \multirow[t]{2}{*}{ Response costs } & Control & $12.93 \pm 3.46$ & $12.41 \pm 4.48$ & $12.61 \pm 4.03$ & 0.306 \\
\hline & Intervention & $12.57 \pm 4.04$ & $9.53 \pm 2.58$ & $10.58 \pm 3.15$ & $<0.001$ \\
\hline \multirow[t]{2}{*}{ Response efficacy } & Control & $15.78 \pm 2.20$ & $15.73 \pm 3.42$ & $15.55 \pm 3.15$ & 0.734 \\
\hline & Intervention & $15.16 \pm 3.40$ & $17.15 \pm 2.42$ & $16.90 \pm 2.67$ & $<0.001$ \\
\hline \multirow[t]{2}{*}{ Self-efficacy } & Control & $16.23 \pm 2.63$ & $16.58 \pm 2.49$ & $16.20 \pm 2.51$ & 0.192 \\
\hline & Intervention & $15.65 \pm 2.66$ & $17.90 \pm 1.29$ & $17.60 \pm 1.38$ & $<0.001$ \\
\hline \multirow[t]{2}{*}{ Rewards } & Control & $11.81 \pm 3.15$ & $11.48 \pm 3.79$ & $11.18 \pm 3.80$ & 0.069 \\
\hline & Intervention & $11.45 \pm 3.63$ & $8.25 \pm 2.73$ & $8.91 \pm 2.75$ & $<0.001$ \\
\hline \multirow[t]{2}{*}{ Awareness } & Control & $4.36 \pm 2.00$ & $4.50 \pm 1.68$ & $4.40 \pm 1.53$ & 0.785 \\
\hline & Intervention & $4.66 \pm 1.90$ & $6.36 \pm 0.75$ & $0.99 \pm 6.01$ & $<0.001$ \\
\hline
\end{tabular}

Values are presented as mean \pm standard deviation. 
tervention, there was no significant difference between the two groups after 2 months.

Several studies in Iran and other countries have supported the effective role of education in protection motivation theory. ${ }^{17,18)}$ Sangchan et al. ${ }^{19)}$ emphasized the role played by free discussion among women about the barriers to breast cancer prevention and ways to overcome the costs of breast cancer. However, Dehdari et al. ${ }^{20)}$ and Ceber et al. ${ }^{21)}$ found that training did not change the mean scores for some constructs, contradicting the results of that study. This discrepancy may reflect differences in the populations, geographical areas, and methods of teaching, in relation to the present study. The present study used the brainstorming method to discuss barriers to preventive action and ways of overcoming each barrier. Practical and acceptable solutions were presented to increase the women's self-efficacy and to build trust and belief in their own ability to engage in healthy-lifestyle behaviors. Movies, question-and-answer sessions, and objective, real examples (including invited breast cancer patients) were some of the educational methods used to help them understand the illness and appreciate its severity. Using different educational methods side-byside appears to have played a decisive role in changing the average scores between the two groups.

In line with the current research, various studies have shown that education plays a significant role in promoting physical activity. ${ }^{22,23)}$ For example, Peyman ${ }^{24)}$ showed that four training sessions achieved a significant change in physical activity after 2 months of educational intervention. It is logical for women to become more committed to adopting healthy behaviors when they are sensitive to the importance and effective role of these behaviors in preventing breast cancer and understand the skills needed to undertake the right kind of physical activity properly.

The findings of the present study showed a significant increase in the intervention group's mean healthy-diet score immediately after the intervention. However, 2 months after the intervention, there was no significant difference between the two groups. Rostami et al. ${ }^{25}$ ) found that 327 health-center employees received sufficient fruit and vegetables to match the pyramid recommendations, contradicting the results of a study in which differences in the type of participants, their occupations, education, and income, were among the reasons for such differences. Although many research findings emphasize the effective role of education in the adoption of nutritional behaviors, ${ }^{26,27)}$ it is undeniable that socially effective health factors play a role in enabling individuals to maintain healthy diets in communities under economic pressure. A study of Hazavehei et al. ${ }^{28)}$ of the promotion of healthy eating habits among 110 elderly people found that two groups of elderly people showed no statistical difference in their intention to adopt nutritional behaviors after 6 weeks of educational intervention.

In their study, Bagherzadeh Aazr et al. ${ }^{29)}$ found that economic power and food choices influenced healthy diet choices. Gustafson ${ }^{30)}$ showed that rising food prices had a negative impact on the Indian population's access to a healthy diet. It seems logical that training women to use vegetable oil and include more units of fruits and vegetables in the family diet would be effective as long as the women could afford to do so. Otherwise, simple awareness of the need will not lead to action in practice. The limitations of this study involved the use of the self-report method and the absence of female employees among the participants. The strengths of this research include its focus on women in a wide range of age groups.

The results suggest that education is effective in promoting behaviors that prevent breast cancer. Training across a wider dimension, using additional tools, and reaching out to more levels of society are suggested approaches to develop this line of research further.

In conclusion, according to the results of this study, protection motivation theory can be effective in promoting women's awareness and physical activity, but educational programs alone cannot guarantee the continuation of behaviors related to a healthy diet, such as the inclusion of more fruit and vegetable units and vegetable oil. The adoption of such healthy behaviors appears to be more influenced by the economic situation of the community.

The key points are as follows: (1) Education based on protection motivation theory is effective in raising the level of physical activity among women. (2) Social components play a role prompting women to follow a healthy diet. (3) Protection motivation theory can provide an appropriate interventional framework for preventive breast cancer practices. (4) Learning to practice healthy lifestyle behaviors is essential for their adoption. (5) Applying different educational methods side-by-side is an effective way of motivating women.

\section{CONFLICTS OF INTEREST}

No potential conflict of interest relevant to this article was reported.

\section{FUNDING}

This study was carried out in 2018, with permission from the Ethics Committee of North Khorasan University of Medical Sciences (code of ethics 960167). It was initially a master's thesis, supported by North Khorasan University of Medical Sciences.

\section{ACKNOWLEDGMENTS}

We are very grateful to all of the women who participated in this study.

\section{ORCID}

Zakieh Sadat Hoseini: https://orcid.org/0000-0002-1282-6569

Hamid Tavakoli Ghouchani: https://orcid.org/0000-0003-3289-7767

Hamidreza Mohaddes Hakak: https://orcid.org/0000-0002-6454-1733

Hossein Lashkardoost: https://orcid.org/0000-0002-1454-7176

Ali Mehri: https://orcid.org/0000-0003-2118-8666

Mehdi Khankolabi: https://orcid.org/0000-0001-9966-9959

Elahe Salari: https://orcid.org/0000-0001-7827-734X 


\section{REFERENCES}

1. Foroughi Z, Janbabaei G, Alizadeh-Navaei R, Hedayatizadeh-Omran A, Eslami M, Geraili B, et al. Iranian cancer research outputs: a scientometric study. J Mazandaran Univ Med Sci 2017;26:206-11.

2. DeSantis CE, Ma J, Goding Sauer A, Newman LA, Jemal A. Breast cancer statistics, 2017, racial disparity in mortality by state. CA Cancer J Clin 2017;67:439-48.

3. Siegel RL, Miller KD, Jemal A. Cancer statistics, 2017. CA Cancer J Clin 2017;67:7-30.

4. Rafiemanesh H, Salehiniya H, Lotfi Z. Breast cancer in Iranian woman: incidence by age group, morphology and trends. Asian Pac J Cancer Prev 2016;17:1393-7.

5. Babu GR, Samari G, Cohen SP, Mahapatra T, Wahbe RM, Mermash S, et al. Breast cancer screening among females in Iran and recommendations for improved practice: a review. Asian Pac J Cancer Prev 2011; 12:1647-55.

6. Zahmatkesh B, Keramat A, Alavi N, Khosravi A, Kousha A, Motlagh AG, et al. Breast cancer trend in Iran from 2000 to 2009 and prediction till 2020 using a trend analysis method. Asian Pac J Cancer Prev 2016;17:1493-8

7. Tahergorabi Z, Moodi M, Mesbahzadeh B. Breast cancer: a preventable disease. J Birjand Univ Med Sci 2014;21:126-41.

8. Luyeye Mvila G, Postema S, Marchal G, van Limbergen E, Verdonck F, Matthijs G, et al. From the set-up of a screening program of breast cancer patients to the identification of the first BRCA mutation in the DR Congo. BMC Public Health 2014;14:759.

9. Froughi Pour A, Ahmadi Faraz M, Dehghani SL. Breast diseases. Esfahan: Kankash Publishing; 2013.

10. Vahedian-Shahrodi M, Pourhaji F, Pourhaji F, Delshad M. Education and prevention of breast cancer. Mashhad: Mashhad University of Medical Science; 2016.

11. Medical and Editorial Content Team, American Cancer Society. Preventive surgery to reduce breast cancer risk [Internet]. Atlanta (GA): American Cancer Society; 2019 [cited 2020 Jan 23]. Available from: https://www.cancer.org/cancer/breast-cancer/risk-and-prevention/ preventive-surgery-to-reduce-breast-cancer-risk.html.

12. Rogers RW. A protection motivation theory of fear appeals and attitude change1. J Psychol 1975;91:93-114.

13. Vadaparampil ST, Jacobsen PB, Kash K, Watson IS, Saloup R, PowSang J. Factors predicting prostate specific antigen testing among firstdegree relatives of prostate cancer patients. Cancer Epidemiol Biomarkers Prev 2004;13:753-8.

14. Haghighi F, Mohammadifard M, Naseh G, Hashem K, Saadatjoo SA. Prevalence of breast cancer among women over 30 years in Birjand between 2009 and 2010. J Birjand Univ Med Sci 2013;20:68-76.

15. Rahaei Z, Mohammadi E, Morowatisharifabad M, Ghofranipour F, Gholami Naserabadi A, Aghaei M, et al. Evaluation of a protection motivation theory-based media program regarding cancer early detection: a mixed-methods study. J Mil Med 2017;19:263-73.

16. Naghibi SA, Moosazadeh M, Shojaizadeh D, Montazeri A, Yazdani Cherati J. The investigate factors on screening of the breast Cancer based on PEN-3 model in Iranian northern women. J Community
Health Res 2015;4:79-90.

17. Gozum S, Karayurt O, Kav S, Platin N. Effectiveness of peer education for breast cancer screening and health beliefs in eastern Turkey. Cancer Nurs 2010;33:213-20.

18. Tazval J, Ghafari M, Mohtashami Yeganeh F, Babazadeh T, Rabati R. Efficiency of protection motivation theory on prediction of skin cancer and sunlight preventive behaviors in farmers in Ilam county. J Health 2016;7:656-67.

19. Sangchan H, Tiansawad S, Yimyam S, Wonghongkul T. The development of a culturally sensitive educational programme to increase the perception, self-efficacy, and practice of Thai Moslem women regarding breast self-examination (BSE). J Health Sci Med Res 2008;26:15-24.

20. Dehdari T, Hassani L, Hajizadeh E, Shojaeizadeh D, Nedjat S, Abedini M. Effects of an educational intervention based on the protection motivation theory and implementation intentions on first and second pap test practice in Iran. Asian Pac J Cancer Prev 2014;15:7257-61.

21. Ceber E, Turk M, Ciceklioglu M. The effects of an educational program on knowledge of breast cancer, early detection practices and health beliefs of nurses and midwives. J Clin Nurs 2010;19:2363-71.

22. Teerarungsikul N, Phuphaibul R, Loveland-Cherry CJ, Pookboonmee R, Kijboonchoo K, Nityasuddhi D. Effectiveness of a physical activity promotion program on perceived self-efficacy, physical activity and physical fitness among Thai adolescent girls. Pac Rim Int J Nurs Res 2009;13:81-94.

23. Seyed Emami R, Eftekhar Ardebili H, Golestan B. Effect of a health education intervention on physical activity knowledge, attitude and behavior in health volunteers. J Hayat 2011;16:48-55.

24. Peyman N. The effect of education based on self-efficacy strategies in changing postpartum physical activity. Med J Mashhad Univ Med Sci 2016;59:328-36.

25. Rostami H, Hashemi G, Homauoni F, Naghavi S. Surveying fruit and vegetable consumption and their associated factors in the staff of the health centers of the Baqiyatallah University of Medical Sciences in 2011. J Mil Med 2014;16:133-9.

26. KhaniJeihooni A, Hatami M, Zarei S, Safdar S, Maleki Z, Akbarzadeh Z. Investigating the effect of educational program based on precede model on the consumption of fruits and vegetables in high school girl students of Fasa city. J Fasa Univ Med Sci 2017;7:361-70.

27. Darabi S, Karimzadeh Shirazi K, Akbar Tabareti M, Mousavizadeh SA, Zamani S. Effect of the implementation of a theory-based educational program on the prevention of cardiovascular diseases in women aged 30 to 45. Armaghane Danesh 2017;22:364-74.

28. Hazavehei MM, Faghih Solaimani P, Moeini B, Soltanian AR, Rahmani K. Evaluation of the educational nutrition intervention's effects on healthy nutritional behaviors promotion in elderly of Sanandaj: application BASNEF model. J Neyshabur Univ Med Sci 2017;5:39-51.

29. Bagherzadeh Azar F, Ranjpour R, Karimi Tu Z, Motafakker M, Assadzadeh A. Estimation and comparison of food security status and the impact of variables: economy on it in the province of Iran. Q J Appl Econ Theory 2016;3:47-76.

30. Gustafson DJ. Rising food costs \& global food security: key issues \& relevance for India. Indian J Med Res 2013;138:398-410. 